\title{
Cocaine preexposure enhances sexual conditioning and increases resistance to extinction in male Japanese quail
}

\author{
Chana K. Akins ${ }^{1}$ • B. Levi Bolin ${ }^{1} \cdot$ Karin E. Gill $^{2}$
}

Published online: 9 May 2017

(C) Psychonomic Society, Inc. 2017

\begin{abstract}
The incentive-sensitization theory posits that drug addiction results from altered learning and motivational processes that stem from drug-induced changes in the brain's reward circuitry. Although it is generally accepted that problematic drug use results from these neuroadaptations, less research has focused on how these neural changes affect the incentive-motivational properties of naturally rewarding stimuli such as sex. The present set of experiments was conducted to investigate (1) dose-dependent effects of preexposure to chronic cocaine on sexual conditioning and (2) how prior cocaine exposure affects the extinction of sexually conditioned behavior in male Japanese quail. In Experiment 1, male quail were exposed to saline or to cocaine $(5,10$, or $20 \mathrm{mg} / \mathrm{kg}$ ip) for 10 days, and their locomotor activity was measured. After a washout period, ten sexual-conditioning trials were conducted in which a light (CS) was presented prior to the presentation of a female quail (US) and approach to the light was measured. The results showed that cocaine dosedependently enhanced sexually conditioned approach behavior and copulation. Experiment 2 was procedurally similar to Experiment 1, except that the quail received either saline or 10 $\mathrm{mg} / \mathrm{kg}$ cocaine (ip) and 24 extinction trials were conducted. During extinction, no female was presented after the CS. The results showed that preexposure to cocaine delayed extinction. Therefore, cocaine may dose-dependently increase the strength of sexual conditioning, and this may subsequently
\end{abstract}

Chana K. Akins

ckakin1@email.uky.edu

1 Department of Psychology, University of Kentucky, 207Q Kastle Hall, Lexington, KY 40506-0044, USA

2 Department of Behavioral Neuroscience, Centre College, Danville, KY, USA increase resistance to extinction. These findings and their possible mechanisms are explored.

Keywords Incentive sensitization · Pavlovian conditioning · Extinction $\cdot$ Sexual behavior $\cdot$ Cocaine $\cdot$ Locomotor activity

It is widely accepted that drugs of abuse act on brain circuitry similar to that activated by naturally rewarding stimuli (see Anselme, 2009, for review). The brain circuits that underlie the encoding of natural rewards are thought to be hijacked by drugs of abuse (Kelley \& Berridge, 2002). This hijacking results in changes in brain regions that are known to affect motivation and reward processing (Kalivas \& O'Brien, 2008; Koob \& Volkow, 2010; Russo et al., 2010; Thomas, Kalivas, \& Shaham, 2008) and thereby are thought to cause changes in the behavior associated with naturally rewarding stimuli.

One theory that may capture how drugs of abuse alter motivation and reward processing is the incentive-sensitization theory proposed by Robinson and Berridge (1993). According to the theory, repeated exposure to drugs of abuse results in changes in the brain circuitry associated with reward. This sensitized reward circuitry may then increase the salience of naturally rewarding stimuli. An increase in the incentive salience of a stimulus may elicit approach responses toward the stimulus.

The incentive-sensitization theory may also account for the heightened or enhanced effects of some drugs of abuse on sexual behavior in humans. Although a few studies have reported impaired effects of psychostimulants on sexual behavior, such as decreased sexual function (Peugh \& Belenko, 2001; see Pfaus, 2010, and Young, Gobrogge, \& Wang, 2011, for reviews), the majority of clinical studies have indicated a heightening or enhancing effect of psychostimulants 
on sexual desire, sexual arousal, and performance (e.g., Green \& Halkitis, 2006; Lorvick et al., 2012; Rawson, Washton, Domier, \& Reiber, 2002; Schilder, Lampinen, Miller, \& Hogg, 2005; Semple, Patterson, \& Grant, 2002). These heightened effects may be due to chronic exposure to psychostimulants that hypersensitize the reward-related neural circuitry (Robinson \& Berridge, 1993).

Preclinical studies have demonstrated similar enhancing effects of psychostimulants on sexual behavior. Fiorino and Phillips (1999) gave amphetamine (AMPH) every other day to male rats, followed by a 21-day withdrawal period, and then tested sexual pursuit in a drug-free state in bilevel chambers. They found that AMPH-exposed males had a greater frequency of level changes during the $5 \mathrm{~min}$ prior to the introduction of the female rat than did saline controls. In addition, AMPHexposed males had higher percentages of mounts and intromissions and a shorter latency to mount and intromit than saline controls. Nocjar and Panksepp (2002) reported similar effects with AMPH. Rats preexposed to repeated AMPH injections and tested after a 14-day withdrawal period showed enhanced sexual pursuit (if the drug was administered in an environment other than the home cage). Similarly, Levens and Akins (2004) demonstrated in male Japanese quail that chronic preexposure to cocaine increased approach behavior to a cue that signaled a mating opportunity (sexual conditioning) when animals were tested 10 days following the last cocaine exposure. Male quail also had shorter latencies to copulate and increased frequencies of copulation. Collectively, these findings suggest that a history of repeated exposure to psychostimulants may enhance the salience of naturally rewarding stimuli, and thereby enhance responding toward those stimuli.

\section{Experiment 1}

Although animal studies have tested various doses of psychostimulants on sexual behavior, systematic studies investigating the dose-dependent effects of psychostimulants on sexual behavior have been scant. Drug dose may be an important determinant of the magnitude of behavioral sensitization and of subsequent alterations in sexual behavior. For example, chronic preexposure to $15 \mathrm{mg} / \mathrm{kg}$ of cocaine (once daily for 7 days) facilitates sexual behavior in male rats, but 30 $\mathrm{mg} / \mathrm{kg}$ of cocaine (once daily for 7 days) severely disrupts sexual behavior (Ferrari \& Giuliani, 1997). Thus, dose appears to be an important determinant of how, and to what degree, drugs of abuse alter sexual behavior.

In the present experiment, a well-established Pavlovian sexual-conditioning paradigm (e.g., Domjan \& Hall, 1986; Domjan, Lyons, North, \& Bruell, 1986; Levens \& Akins, 2004) was used to determine the dose-dependent effects of cocaine on sexual motivation and performance in male
Japanese quail. In Pavlovian sexual conditioning, an arbitrary object (the conditioned stimulus, or CS) is repeatedly paired with an opportunity to mate with a female conspecific (US or reward). After several pairings, the CS elicits approach behavior (Domjan et al., 1986). As in previous studies (e.g., Levens \& Akins, 2004), animals were preexposed to drugs chronically and then tested in a drug-free state after a rest period. This is typically done to avoid any potentially confounding physiological effects of the drugs (e.g., stereotypy) that might interfere with performance and/or blunt the rewarding properties of sex. This procedure also avoids context-dependent learning. In addition, testing during withdrawal or after a rest period allows for investigating the relatively long-term effects of a drug on sexual behavior.

\section{Method}

\section{Subjects}

The subjects were 71 adult male Japanese quail (Coturnix japonica), 2-3 months old. Eggs (Northwest Gamebirds, Kennewick, WA) were hatched and the quail chicks were raised in mixed-sex groups until approximately 28 days of age. At 28 days of age, the quail were housed individually in wire mesh cages (Georgia Quail Farm Manufacturing, Savannah, GA). Thirty-two age-matched sexually mature female quail were used as copulation partners during the sexualconditioning phase. All subjects were drug and sexually naïve prior to experimentation. Lights were kept on in the colony room from 0600 to $2200 \mathrm{~h}$ to maintain the quail in a state of reproductive readiness. Food and water were available ad libitum, and animal care and the experimental procedures were conducted according to the guidelines of the Institutional Animal Care and Use Committee (IACUC) at the University of Kentucky.

\section{Drugs}

Cocaine hydrochloride (National Institute of Drug Abuse, Bethesda, MD) was dissolved in saline $(0.9 \% \mathrm{NaCl})$ and injected intraperitoneally (ip) at a volume of $1 \mathrm{ml} / \mathrm{kg}$. The doses were 5,10 , or $20 \mathrm{mg} / \mathrm{kg}$. This selection of doses was based on previous cocaine sensitization experiments in male Japanese quail (e.g., Geary \& Akins, 2007; Levens \& Akins, 2004).

\section{Apparatus}

Locomotor activity was assessed in chambers that measured $28.6 \mathrm{~cm}$ long $\times 21.2 \mathrm{~cm}$ wide $\times 21.2 \mathrm{~cm}$ deep (Med Associates, St. Albans, VT). Each chamber was equipped with six photobeams spaced approximately $6.4 \mathrm{~cm}$ apart and 
$3.2 \mathrm{~cm}$ above the floor. Photobeam breaks were recorded by the MedPC IV software (Med Associates, St. Albans, VT).

Six large Plexiglas test cages $(91.4 \mathrm{~cm}$ wide $\times 61.0 \mathrm{~cm}$ deep $\times 30.5 \mathrm{~cm}$ tall) were used during sexual conditioning. The side walls of the cages were covered with white paper, and the floors of the cages were covered with white corrugated paper. A smaller Plexiglas side cage $(30.5 \mathrm{~cm}$ wide $\times 61.0 \mathrm{~cm}$ deep $\times$ $27.9 \mathrm{~cm}$ tall) was attached to one end of each test cage and was used to house a female bird. A door connecting the test cage and the side cage allowed male quail to access the female's side cage. The door was covered with white paper so that the males and females could not see each other unless the door was opened. A $25-\mathrm{W}$ red light served as the conditioned stimulus (CS). The CS light was located approximately $15.24 \mathrm{~cm}$ above the floor. A $36.6 \mathrm{~cm} \times 36.6 \mathrm{~cm}$ area was marked on the white paper floor beneath each light and was referred to as the CS zone.

The locomotor activity chambers, sexual-conditioning test cages, and home cages were located in separate rooms. Throughout the experiment, subjects were housed in their individual home cages and were only placed in either the locomotor activity chambers or test cages during testing.

\section{Procedure}

Locomotor activity A procedure similar to that used in previous experiments (e.g., Geary \& Akins, 2007) was used to measure locomotor activity. Male quail were injected (ip) with either saline (SAL) or 5,10 , or $20 \mathrm{mg} / \mathrm{kg}$ cocaine (COC) and were immediately placed in locomotor chambers. Photobeam breaks were recorded for $30 \mathrm{~min}$. Ten trials were conducted, one per day. White noise was used during locomotor-activity sessions to attenuate extraneous noise. The locomotor-activity phase was followed by a 7- to 10-day rest period, during which time the quail were housed in their home cages.

Sexual conditioning Habituation sessions were conducted once daily during the last four days of the rest period. During habituation, male quail were given free access to the sexual-conditioning test chambers for $30 \mathrm{~min}$ each day while no females were present. After habituation and the 7- to 10day rest period, sexual conditioning began in the test chambers. Male quail were randomly assigned to one of eight groups: paired-COC $5(n=11)$, unpaired-COC $5(n=8)$, paired-COC $10(n=9)$, unpaired-COC $10(n=8)$, pairedCOC $20(n=10)$, unpaired-COC $20(n=8)$, paired-SAL $(n=$ $10)$, and unpaired-SAL $(n=7)$. The COC 5,10 , or 20 groups received 5,10 , or $20 \mathrm{mg} / \mathrm{kg}$ cocaine during the locomotor activity phase (above), respectively. The SAL groups received only saline. (The $n$ 's were chosen on the basis of Geary \& Akins, 2007, who used $n$ 's of 7-8 to investigate dose effects on cocaine-induced locomotor activity.)
During each conditioning trial, male quail were placed in the center of the test cage for a 30-sec pre-CS baseline period. Following the pre-CS period, the CS light was illuminated for $30 \mathrm{sec}$ and was then turned off. Subsequently, for paired males, the door to the female's side cage was raised, and the males invariably entered the side cage for a copulatory opportunity with a female quail for $5 \mathrm{~min}$. Unpaired males received the same treatment, except that they received a 5-min copulatory opportunity with a female bird in their home cage 2-3 h before each sexual-conditioning trial. The female copulation partners were rotated such that no male copulated with the same female more than twice. White noise was used to attenuate extraneous noise during all trials. Ten sexualconditioning trials were conducted, one per day.

During the CS period, time spent in the CS zone was recorded whenever a male quail had both feet inside of the CS zone. During each copulatory opportunity, the frequency of cloacal contact movements (CCMs) was recorded as a measure of sexual performance. CCMs are highly stereotyped behaviors that occur when the male's cloaca makes contact with the cloaca of the female. Frequencies of CCMs are commonly used as an index of sexual performance in quail because foam and semen are transferred into the female's cloaca via the male's cloacal gland during copulation, representing a successful copulatory event (Mills, Crawford, Domjan, \& Faure, 1997).

\section{Statistical analyses}

Locomotor-activity data were expressed as mean photobeam breaks and analyzed with a 4 (Treatment) $\times 10$ (Trials) repeated measures analysis of variance (ANOVA). For approach behavior data during the sexual-conditioning phase, an overall repeated measures ANOVA with pairing and treatment as between-group variables and trials as the repeated measure were conducted. Subsequently, independent repeated measures ANOVAs were conducted for the paired and unpaired groups separately. Copulatory behavior (CCMs) was collapsed across trials and analyzed with pairing and treatment as between-subjects variables in an ANOVA. Where appropriate, simple main effect tests were used for further analysis and Fisher's protected LSD post hoc tests were used. The alpha level for each statistical analysis was set at $p<.05$.

\section{Results}

Figure 1 illustrates the mean photobeam breaks across trials for birds that received saline and cocaine. There was a significant Treatment $\times$ Trials interaction, $F(27,603)=1.94, p<$ .01 , suggesting that locomotor activity across trials was different for birds that received cocaine rather than saline. Birds that received cocaine showed a significant increase in locomotor activity across trials, resulting in a significant main effect of 


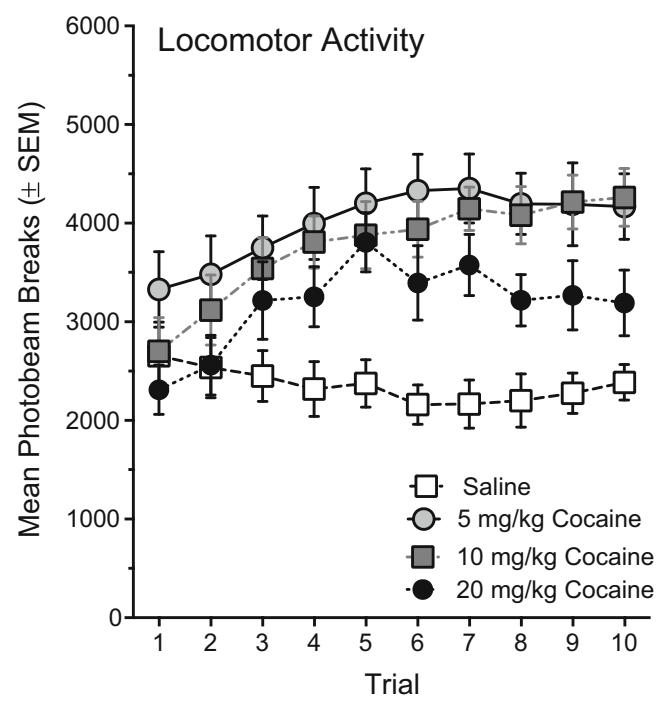

Fig. 1 Mean $( \pm S E M)$ photobeam breaks across trials for male quail treated with saline or 5,10 , or $20 \mathrm{mg} / \mathrm{kg}$ cocaine

trials for each cocaine group, with $F$ s ranging from 2.4 to 6.1 . Birds receiving saline did not show an increase in locomotor activity across trials, $F(9,153)=0.8$. The repeated measures ANOVA also revealed main effects of trials, $F(9,603)=6.01$, $p<.001$, and treatment, $F(3,67)=10.31, p<.001$. Cocaine doses of $5 \mathrm{mg} / \mathrm{kg}(M=4,000.86, S E M=114.23), 10 \mathrm{mg} / \mathrm{kg}(M$ $=3,770.39, S E M=100.07)$, and $20 \mathrm{mg} / \mathrm{kg}(M=3,181.17$, $S E M=103.79)$ all elicited greater numbers of photobeam breaks than did saline $(M=2,353.82, S E M=80)$. Further analysis using Fisher's protected LSD test showed that the mean photobeam breaks were significantly greater for subjects treated with 20,10 , and $5 \mathrm{mg} / \mathrm{kg}$ cocaine than for subjects treated with saline (minimum mean differences were 827.35, $1,416.57$, and 1,647.04, respectively, $p$ 's <.01). Similarly, the LSD analysis indicated that the $5 \mathrm{mg} / \mathrm{kg}$ cocaine group demonstrated more locomotor activity than the $20-\mathrm{mg} / \mathrm{kg}$ cocaine group (mean minimum difference $=819.69, p<.01$ ).

Figure 2 represents mean time spent in the CS zone across trials for the paired (top panel) and unpaired (bottom panel) groups. An overall repeated measures ANOVA indicated a significant Pairing $\times$ Trials interaction, $F(9,567)=9.53, p<$ .001 , suggesting a difference in approach behavior across trials for the paired and unpaired groups. A subsequent independent repeated measures ANOVA for the paired groups revealed a main effect of treatment, $F(1,11)=29.11, p<.001$. Fisher's protected LSD analyses showed that paired subjects that were preexposed to cocaine doses of $10 \mathrm{mg} / \mathrm{kg}(M=$ 23.32, $S E M=0.94)$ and $20 \mathrm{mg} / \mathrm{kg}(M=22.13, S E M=0.85)$ spent significantly greater amounts of time in the goal zone during the CS period than did subjects that were preexposed to saline $(M=15.40, S E M=1.01), t(8)=6.73$ and $t(9)=7.92$, respectively. Fisher's protected LSD analyses also indicated that the subjects previously treated with $10 \mathrm{mg} / \mathrm{kg}$ cocaine $(M$ $=23.32, S E M=0.94)$ spent significantly more time in the goal
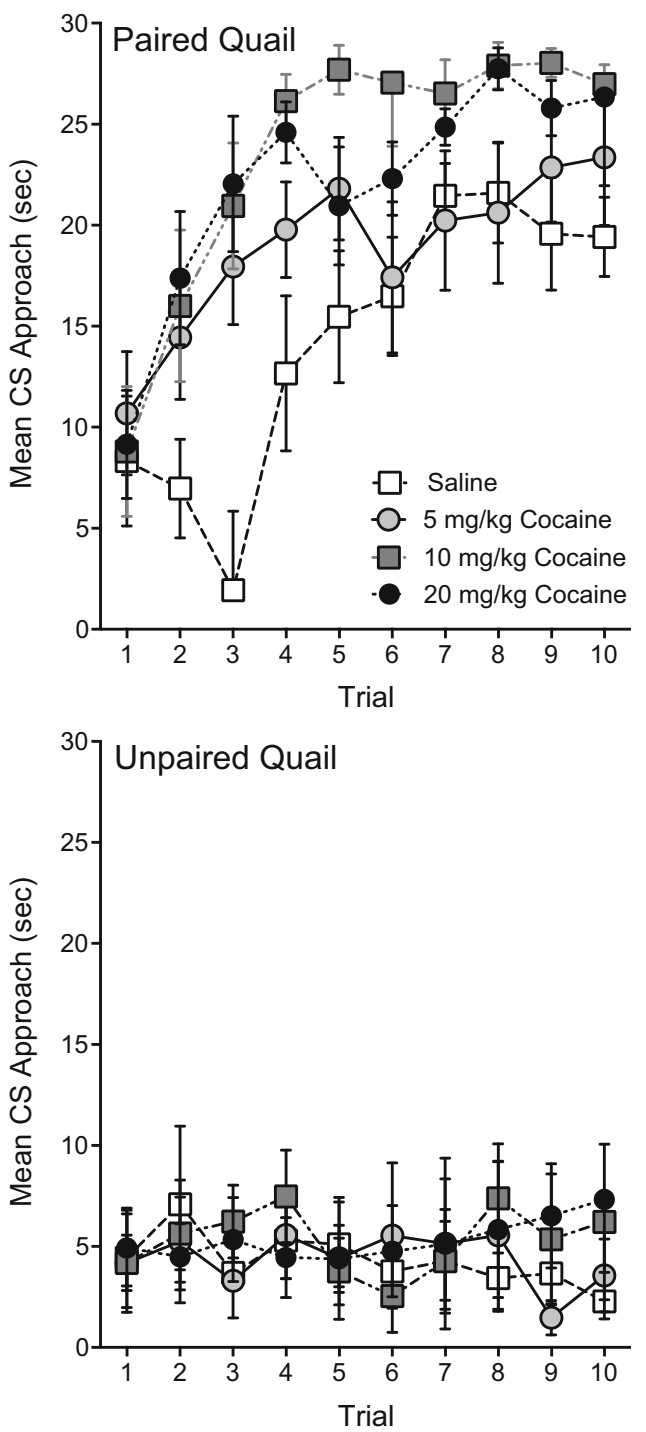

Fig. 2 Mean $( \pm S E M)$ time spent in the conditioned stimulus (CS) zone across trials for paired (top panel) and unpaired (bottom panel) male quail that received saline or 5,10 , or $20 \mathrm{mg} / \mathrm{kg}$ cocaine

zone during the CS period than did subjects preexposed to 5 $\mathrm{mg} / \mathrm{kg}$ cocaine $(M=18.92, S E M=1.00)$, mean minimum difference $=4.39, p<.05$. We observed no significant Treatment $\times$ Trials interaction for the paired groups, $F(9,99)$ $=0.68$, suggesting that the cocaine and saline treatment groups had similar acquisition during sexual conditioning. The repeated measures ANOVA for unpaired subjects did not result in any significant main effects or interactions, all $F$ 's $<0.47$.

The frequencies of CCMs for paired (top panel) and unpaired (bottom panel) males, collapsed across trials, are shown in Fig. 3. An ANOVA failed to show a significant Pairing $\times$ Treatment interaction, $F(3,63)=0.31$. However, a significant main effect of treatment suggested that male quail that were preexposed to cocaine made significantly more CCMs with a female quail than did the other treatment groups, regardless of 

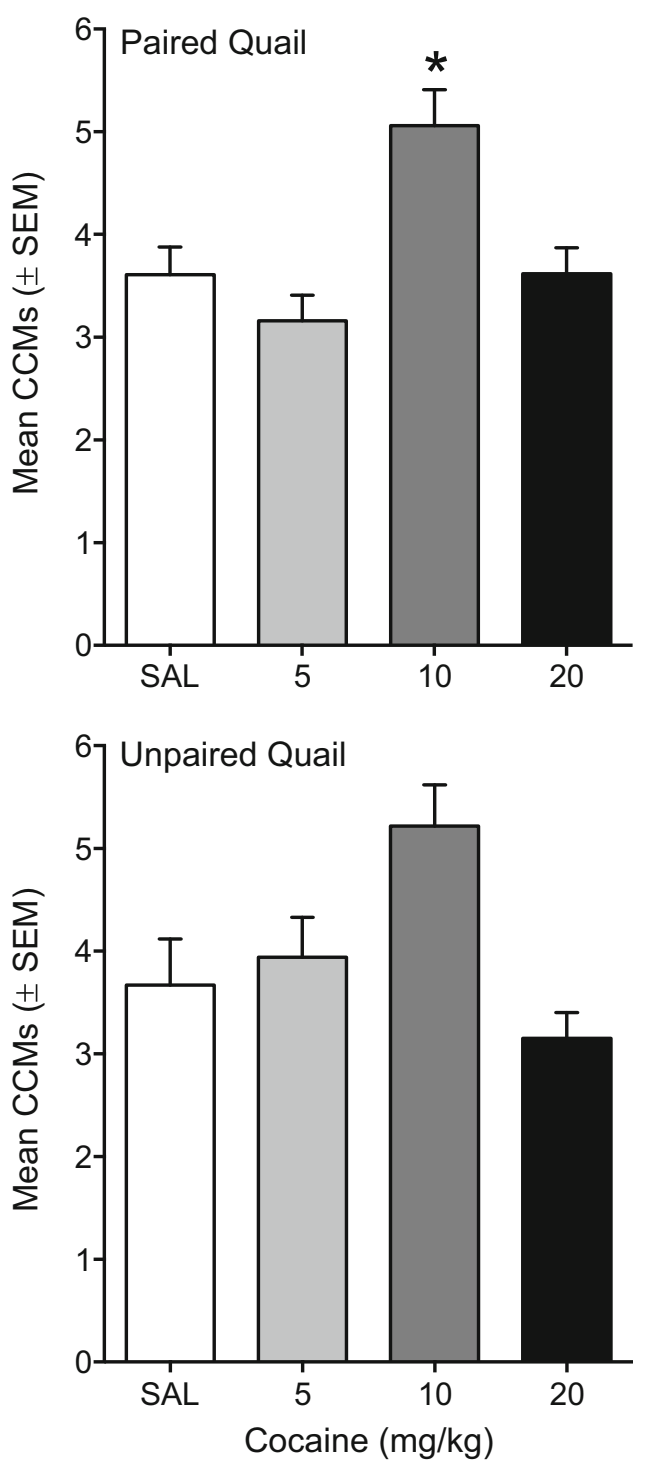

Fig. 3 Mean frequencies of cloacal contact movements (CCMs), collapsed across trials, for paired (top panel) and unpaired (bottom panel) subjects treated with saline or cocaine. "significant difference from saline $(p<.05)$

pairing, $F(3,63)=3.11$. A Fisher's protected LSD post hoc analysis further showed that quail preexposed to $10 \mathrm{mg} / \mathrm{kg}$ cocaine $(M=5.14, S E M=0.26)$ made more CCMs than did the other groups (Ms ranged from 3.41 to 3.64 , SEMs from 0.18 to 0.25 ), with mean minimum differences ranging from 1.5 to $1.72, p s<.05$.

\section{Discussion}

The present experiment was conducted to determine whether chronic preexposure to cocaine would dose-dependently enhance sexually conditioned approach behavior in male Japanese quail. During the preexposure phase, locomotor activity was increased for quail treated with all doses of cocaine as compared to saline across trials. In addition, the 5 and 10 $\mathrm{mg} / \mathrm{kg}$ doses of cocaine induced more activity than the $20 \mathrm{mg} /$ $\mathrm{kg}$ dose. These findings are generally congruent with previous research conducted in our laboratory (Akins, Levens, Prather, Cooper, \& Fritz, 2004; Levens \& Akins, 2001, 2004), except that Geary and Akins (2007) found that $20 \mathrm{mg} / \mathrm{kg}$ cocaine produced greater locomotor activity than either 5 or $10 \mathrm{mg} /$ $\mathrm{kg}$; however, they injected quail and placed them in the activity chamber for $150 \mathrm{~min}$, rather than the $30 \mathrm{~min}$ in the present study. It is possible that, in Geary and Akins's experiment, longer exposure to the drug-paired context may have resulted in a learned effect.

Previous research with rodents has demonstrated that repeated exposure to psychostimulants may enhance sex-seeking and copulatory behavior after a rest period (Fiorino \& Phillips, 1999; Nocjar \& Panksepp, 2002). Levens and Akins (2004) demonstrated that male quail preexposed to $10 \mathrm{mg} / \mathrm{kg}$ cocaine exhibited more conditioned approach to the CS, a greater number of CCMs, and a shorter latency to copulate with a female than did quail that were preexposed to saline. The present experiment replicated these results in the $10 \mathrm{mg} / \mathrm{kg}$ cocaine group, but additionally showed that male quail that were preexposed to $20 \mathrm{mg} / \mathrm{kg}$ cocaine also spent significantly more time in the goal zone during the CS period than did quail that were preexposed to saline. These results suggest that sexual conditioning that occurs after preexposure to cocaine is dose-dependent and that doses of 10 and $20 \mathrm{mg} / \mathrm{kg}$ facilitate sexual conditioning in Japanese quail.

\section{Experiment 2}

In Experiment 1, cocaine may have strengthened the CS-US association during sexual conditioning. The effect of cocaine on the extinction of sexual conditioning has not been explored. Therefore, the purpose of the present experiment was to determine the effect of chronic preexposure to cocaine on the extinction of sexually conditioned responding to an arbitrary CS in male Japanese quail. We hypothesized that male quail that were preexposed to cocaine would persist in approach to a CS that reliably predicted a mating opportunity with a female conspecific, relative to male quail that received saline.

\section{Method}

\section{Subjects}

The subjects were 32 adult male Japanese quail (Coturnix japonica), 2-3 months old, and were treated similarly to those in Experiment 1.

The data from one subject were not included in the analyses because the bird failed to copulate with a female partner 
throughout the experiment. In addition, the data from two additional subjects that were identified as outliers with a Grubbs extreme Studentized deviate test (Grubbs, 1969) were excluded from the statistical analyses.

\section{Drugs}

Cocaine hydrochloride was prepared similarly as in Experiment 1. The dose was chosen on the basis of the results of Experiment 1 and prior experiments (e.g., Geary \& Akins, 2007; Levens \& Akins, 2001).

\section{Apparatus}

The same apparatus was used as in Experiment 1.

\section{Procedure}

The experimental design was a $2 \times 2$ with pairing (unpaired vs. paired) and treatment (cocaine vs. saline) as between-group variables and trial as a repeated measure. The groups were unpaired cocaine $(n=7)$, unpaired saline $(n=10)$, paired cocaine $(n=6)$, and paired saline $(n=6)$.

Locomotor activity Locomotor activity was assessed in a manner similar to that in Experiment 1, except that male quail were injected ip with $10 \mathrm{mg} / \mathrm{kg}$ cocaine and then placed in the locomotor activity chambers for $30 \mathrm{~min}$. Trials were conducted once a day for 10 days and were followed by a 10-day rest period.

Sexual conditioning Sexual conditioning was conducted similarly to Experiment 1, except that only ten conditioning trials were conducted, one per day.

Extinction The extinction trials were identical to the sexual-conditioning trials, except that no copulatory opportunity was given and no females were present in the side chambers. Twenty-four extinction trials were conducted, one per day.

\section{Statistical analysis}

Photobeam break data were analyzed in a 2 (Treatment) $\times 10$ (Trials) repeated measures ANOVA. Approach and extinction data from the sexual-conditioning phase were analyzed similarly, with an overall repeated measures ANOVAs of the paired and unpaired groups and subsequent separate repeated measures ANOVAs. In addition, to assess treatment differences on each sexual-conditioning and extinction trial, $t$ tests were conducted. A Bonferroni correction was implemented to avoid Type I errors. The alpha level for each statistical analysis was set at $p<.05$.

\section{Results}

\section{Locomotor activity}

Figure 4 shows the mean photobeam breaks for male quail treated with saline or $10 \mathrm{mg} / \mathrm{kg}$ cocaine. Quail treated with $10 \mathrm{mg} / \mathrm{kg}$ cocaine $(M=4,190, S E M=111.05)$ showed greater locomotor activity than quail treated with saline $(M=$ 2,728.08, SEM = 74.81), both overall and across trials. A one-way repeated measures ANOVA revealed a significant main effect of treatment, $F(1,26)=27.03, p<.01$, and a significant Treatment $\times$ Trials interaction, $F(9,234)=2.63$, $p<.01$. The main effect of Trials was also significant, $F(9$, 234) $=3.14, p<.01$.

\section{Sexual conditioning}

Figure 5 illustrates the mean time spent in the CS zone during the sexual-conditioning phase of Experiment 2 for paired (top panel) and unpaired (bottom panel) male quail treated with saline or $10 \mathrm{mg} / \mathrm{kg}$ cocaine. A repeated measures ANOVA indicated a significant Pairing $\times$ Treatment $\times$ Trials interaction, $F(9,216)=5.44, p<.001$. A separate ANOVA on the paired groups indicated that paired quail treated with $10 \mathrm{mg} /$ $\mathrm{kg}$ cocaine $(M=21.67, S E M=0.92)$ showed greater approach to the CS than did paired quail that were treated with saline ( $M$ $=12.87, S E M=0.87$ ). This was evident as a significant main effect of Treatment, $F(1,10)=26.97, p<.001$. We also found a significant main effect of Trials, $F(9,90)=12.74, p<.001$, but no significant Treatment $\times$ Trials interaction, $F(9,90)=$ 0.5 . Our $t$-test analyses with a Bonferroni correction showed

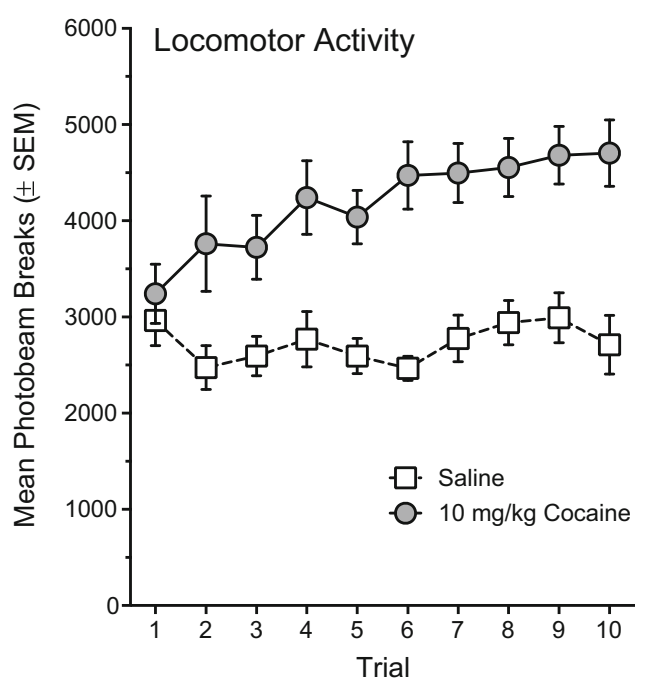

Fig. 4 Mean $( \pm S E M)$ photobeam breaks for male quail treated with saline or $10 \mathrm{mg} / \mathrm{kg}$ cocaine 

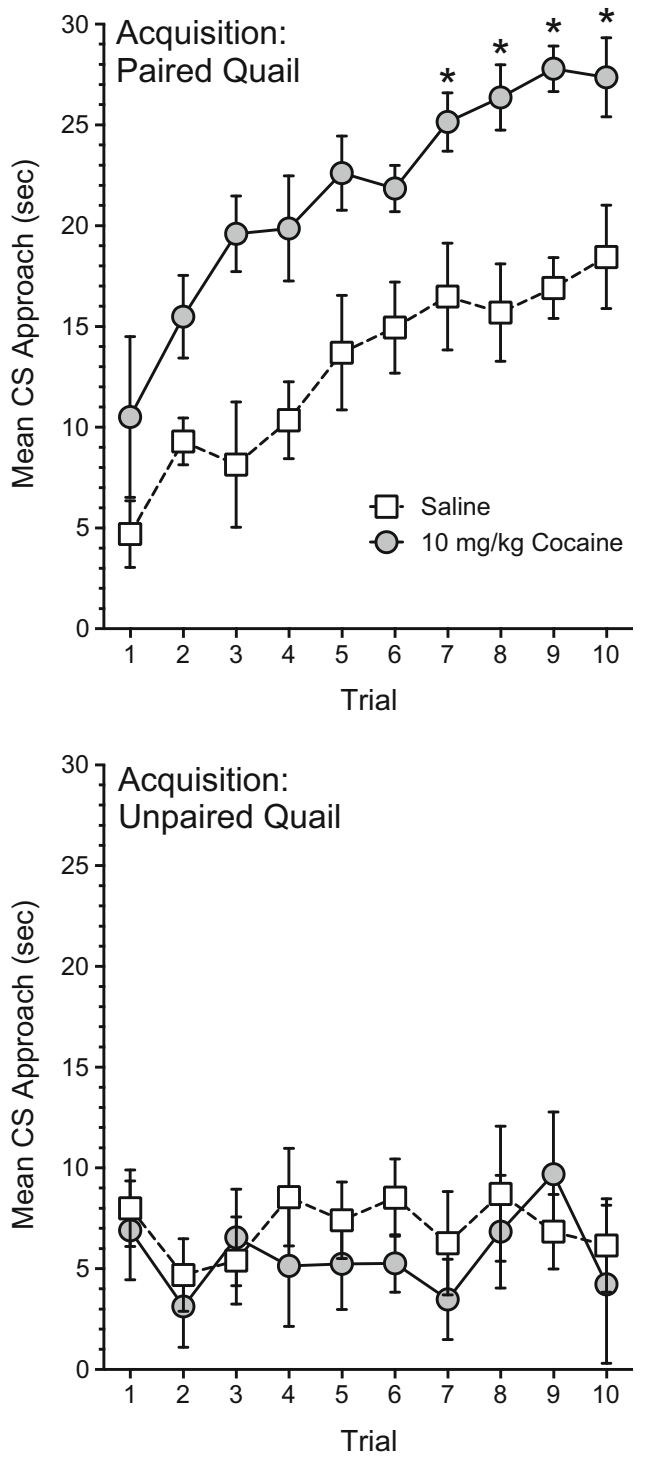

Fig. 5 Mean $( \pm S E M)$ time spent near the conditioned stimulus (CS) during sexual conditioning for paired (top panel) and unpaired (bottom panel) male quail treated with saline or $10 \mathrm{mg} / \mathrm{kg}$ cocaine. significant difference from saline $(p<.05)$

that cocaine paired subjects had significantly greater approach to the CS than saline paired subjects on Trials $7,8,9$, and 10 ( $t$ 's of 2.87, 3.66, 5.77, and 2.76, respectively, $p$ 's $<.05$.

The ANOVA on time spent near the CS for the unpaired saline and cocaine groups failed to reveal any significant main effects or interactions, $F \mathrm{~s}$ ranging from 0.41 to 0.80 .

\section{Extinction}

Figure 6 represents time spent near the CS (in seconds) during the extinction trials for male quail preexposed to saline or cocaine $(10 \mathrm{mg} / \mathrm{kg})$ in the paired (top panel) and unpaired (bottom panel) groups. The repeated measures ANOVA with treatment and pairing as between-subjects measures showed
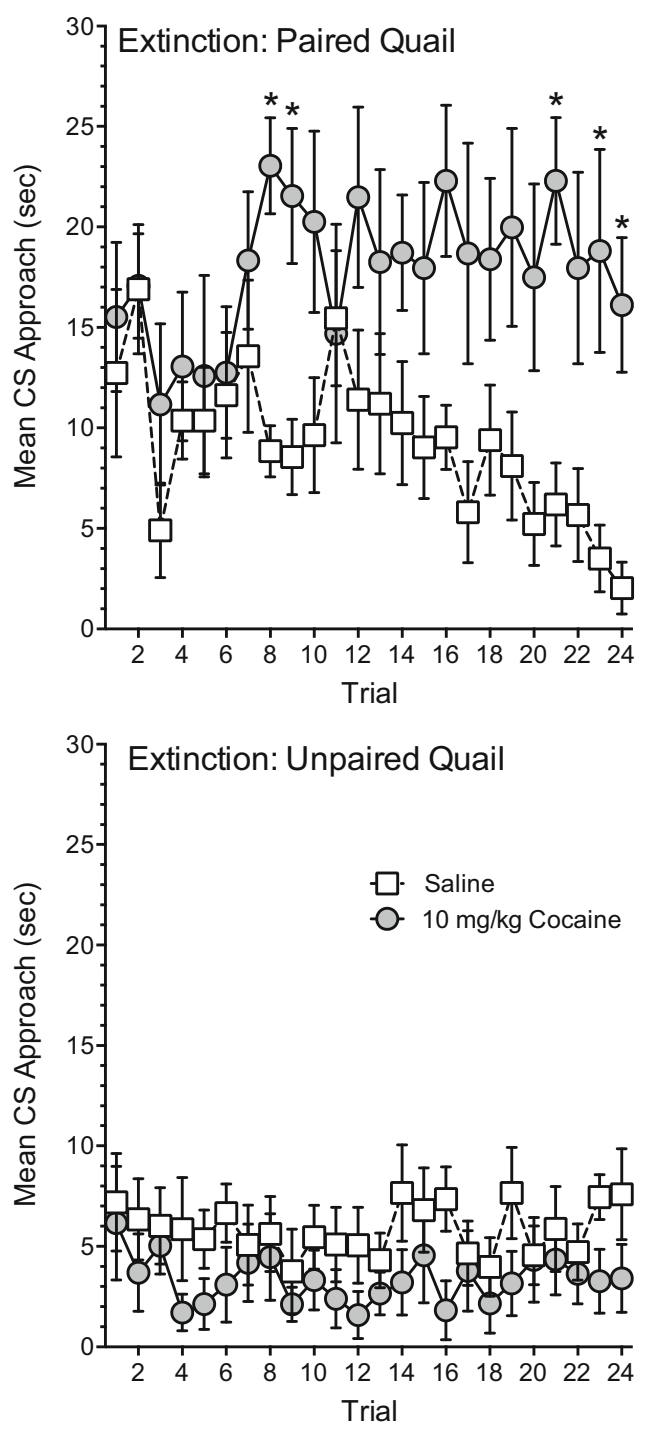

Fig. 6 Mean $( \pm S E M)$ time spent near the conditioned stimulus (CS) during extinction trials for paired (top panel) and unpaired (bottom panel) male quail treated with saline or $10 \mathrm{mg} / \mathrm{kg}$ cocaine. ${ }^{*}$ significant difference from saline $(p<.05)$.

that the paired and unpaired subjects responded differently across trials, $F(23,552)=1.35, p<.05$. A separate ANOVA for the paired subjects indicated that paired male quail with a history of treatment with $10 \mathrm{mg} / \mathrm{kg}$ cocaine $(M=17.85, S E M$ $=0.59)$ spent more time near the CS during extinction than did their paired saline controls $(M=9.18, S E M=0.59)$. This was evident as a significant main effect of Treatment, $F(1,10)=$ $31.04, p<.001$. We found no significant main effect of Trials, $F(1,23)=0.93$, nor a significant Treatment $\times$ Trials interaction, $F(23,230)=1.16$. However, $t$-test analyses with a Bonferroni correction revealed that the cocaine paired subjects had significantly greater approach than did saline paired subjects on Trials $8,9,21,23$, and 24 (Fig. 6 top panel), $t$ 's of $5.24,3.37,4.27,3.87$, and 3.92, respectively, $p$ 's $<.002$. 
The ANOVA for unpaired subjects that received either cocaine or saline did not indicate any significant main effects $(F$ 's were 2.26 for treatment and 0.82 for trials), nor a significant Treatment $\times$ Trials interaction, $F(23,322)=0.51$.

It should be noted that the first extinction trial (Fig. 6) is much lower and looks different from the last acquisition trial (Fig. 5). This may have been due to the absence of the female in the side cage, and hence the absence of the noise and smell of the female. Typically, these conditions are not sufficient to result in conditioning (Domjan et al., 1986). Although they may have in the current experiment, they do not appear to account for the treatment differences across extinction.

\section{General discussion}

Experiment 1 demonstrated that chronic preexposure to cocaine dose-dependently enhanced sexual conditioning. The finding that cocaine enhances or facilitates sexual motivation in an animal model corroborates clinical self-reports that provide evidence for heightening effects of psychostimulants on sexual desire and arousal in humans (e.g., Green \& Halkitis, 2006; Lorvick et al., 2012; Rawson et al., 2002; Schilder et al., 2005: Semple et al., 2002). Indeed, preclinical studies have demonstrated similar facilitative effects of psychostimulants on sexual motivation (e.g., Fiorino \& Phillips, 1999; Levens \& Akins, 2004; Nocjar \& Panksepp, 2002). In addition, the findings of Experiment 1 provide support for the incentivesensitization theory, in that chronic preexposure to cocaine facilitated sexual conditioning for a relatively long period after discontinuing administration. In accordance with the theory, chronic cocaine may have sensitized the reward neural circuitry (evident as increased locomotor activity) and subsequently enhanced responding to sex-related stimuli (the CS that predicted sex).

An alternative explanation is that cocaine did not directly influence learning (the CS-US association), but instead affected the incentive salience or enhancement of the US alone. In Experiment 1 overall, the paired cocaine birds made more cloacal contacts (copulations) than did the saline birds. This was not evident in unpaired cocaine birds, but the latter did have an increase in cloacal contacts across trials. This finding replicates the findings of previous sexual-conditioning studies (Fiorino \& Phillips, 1999; Levens \& Akins, 2004) and suggests that preexposure to cocaine may have facilitated some unconditioned sexual behavior.

Experiment 2 of the present research demonstrated that chronic preexposure to cocaine facilitated sexual conditioning and subsequently delayed extinction. Male quail that received cocaine were slower to extinguish conditioned approach to a stimulus that predicted the presentation of a female, relative to quail that received saline. This is a relatively novel and important finding with regard to the mechanism of cocaine on extinction. Few studies have been conducted to investigate the impact of prior drug exposure on the extinction of conditioned responding, and the outcomes of these studies have been mixed. For example, research with amphetamine has shown that doses that enhance the acquisition of conditioned fear had no effect on the extinction of conditioned fear in mice (Carmack, Wood, \& Anagnostaras, 2010) or conditioned approach in rats (Blaiss \& Janak, 2007). On the contrary, a history of repeated exposure to cocaine significantly delayed the extinction of conditioned freezing and suppression in a fearconditioning procedure in rats that were tested in a drug-free state following 21 days of withdrawal (Burke, Franz, Gugsa, \& Schoenbaum, 2006). Similarly, Bevins and associates (Murray \& Bevins, 2007; Reichel, Murray, Barr, \& Bevins, 2010) found that nicotine-induced responding persisted throughout extinction and that this effect was dose-dependent. The present findings are consistent with the latter findings and extend the previous findings to sexual conditioning, suggesting that higher doses of cocaine increase resistance to extinction of a sexually conditioned response.

It is unclear whether the persistence of sexually conditioned responding in the present study reflects enhanced cocaine-induced learning or, rather, that prior cocaine exposure impaired the ability to learn a new response or withhold an inappropriate response during extinction. Previous research with nonhuman primates has shown that chronic cocaine selfadministration $(3.0 \mathrm{mg} / \mathrm{kg} /$ day for 4 days over 9 months) produced deficits in reversal learning in a stimulus discrimination task, despite accurate performance during initial acquisition of the discrimination (Porter et al., 2011). Furthermore, similar behavioral inflexibility has been reported with human drug users in procedures involving reversal learning (Ersche, Roiser, Robbins, \& Sahakian, 2008; Fillmore \& Rush, 2006). For example, Fillmore and Rush (2006) used a cued go/no-go task in which the particular orientation of a rectangle served as a discriminative stimulus for the presentation of go or no-go targets. When the orientation of the cues was reversed in the discrimination-reversal phase, control subjects showed reversal learning, whereas cocaine/alcohol abusers did not show reversal learning for response inhibition or activation, despite similar performance during acquisition (Fillmore \& Rush, 2006). These findings suggest that a history of drug use may interfere with learning about stimulus-response or stimulus-outcome relationships that are incongruent with prior learning. Therefore, it is possible that the resistance to extinction of sexually conditioned behavior in the present experiment may reflect processes other than those due to the strengthening of learning during acquisition.

Previous research on extinction might provide insight into the potential mechanisms responsible for the persistence of conditioned responding during extinction in the present study. 
Some studies have suggested that the greater the level of activation of the US representation by the CS(s) during extinction, the larger the corresponding decrement in associative strength between the CS and US (e.g., Delamater, 2004; Mackintosh, 1974; Rescorla, 2000). Although the procedures used in Experiment 2 do not permit the explicit evaluation of this hypothesis, it is possible that a history of repeated exposure to cocaine decreased the level of activation of the US representation during extinction, slowing the progression of extinction learning relative to quail that received saline. Future studies will be needed to determine whether cocaine might alter the activation of the US representation in the extinction of sexually conditioned approach behavior.

A complementary explanation is that neuroadaptations resulting from prior cocaine exposure may have altered plasticity-dependent processes that are necessary for learning a new stimulus-outcome relationship during extinction. In particular, cocaine exposure alters central glutamate and dopamine function to disrupt normal plasticity in the medial prefrontal cortex, a brain region that is hypothesized to be critically involved in extinction learning (Kalivas, 2004; Kalivas, Volkow, \& Seamans, 2005; Morgan, Romanski, \& LeDoux, 1993; Robinson \& Kolb, 1999). These lasting changes in neural function may have been at least partly responsible for the persistence of conditioned responding to the $\mathrm{CS}$ in cocaine-treated quail across extinction, relative to saline treated quail. Regardless of the specific behavioral and neural mechanism(s) involved, increased resistance to the extinction of sexually conditioned responses may play a role in the pervasive prevalence and persistence of maladaptive sexual behavior in drug users.

Author note Financial support for this research was provided by NIDA Grant No. DA022451 awarded to C.K.A. The authors have no conflicts of interest relevant to this research to disclose. The authors thank Emily Reinhardt, Samantha Barton, Luke Cornett, Noelle Davis, Sammy Schwienher, Megan Varner, and Patrick Young for their assistance with data collection and animal care.

\section{References}

Akins, C. K., Levens, N., Prather, R., Cooper, B., \& Fritz, T. (2004). Dose-dependent cocaine place conditioning and D1 dopamine antagonist effects in male Japanese quail. Physiology \& Behavior, 82, 309-315.

Anselme, P. (2009). The effect of exposure to drugs on the processing of natural rewards. Neuroscience \& Biobehavioral Reviews, 33, 314 335.

Blaiss, C. A., \& Janak, P. H. (2007). Post-training, but not post-reactivation, administration of amphetamine and anisomycin modulates Pavlovian conditioned approach. Neurobiology of Learning and Memory, 87, 644-658.

Burke, K. A., Franz, T. M., Gugsa, N., \& Schoenbaum, G. (2006). Prior cocaine exposure disrupts extinction of fear conditioning. Learning and Memory, 13, 416-421.
Carmack, S. A., Wood, S. C., \& Anagnostaras, S. G. (2010). Amphetamine and extinction of cued fear. Neuroscience Letters, $468,18-22$.

Delamater, A. R. (2004). Experimental extinction in Pavlovian conditioning: Behavioural and neuroscience perspectives. Quarterly Journal of Experimental Psychology B, 57, 97-132.

Domjan, M., \& Hall, S. (1986). Determinants of social proximity in Japanese quail (Coturnix coturnix japonica): Male behavior. Journal of Comparative Psychology, 100, 59-67.

Domjan, M., Lyons, R., North, N. C., \& Bruell, J. (1986). Sexual Pavlovian conditioned approach behavior in male Japanese quail (Coturnix coturnix japonica). Journal of Comparative Psychology, 100, 413-421.

Ersche, K. D., Roiser, J. P., Robbins, T. W., \& Sahakian, B. J. (2008), Chronic cocaine but not chronic amphetamine use is associated with perseverative responding in humans. Psychopharmacology (Berlin), 197, 421-431.

Ferrari, F., \& Giuliani, D. (1997). Involvement of dopamine D2 receptors in the effect of cocaine on sexual behavior and stretching-yawning of male rats. Neuropharmacology, 36, 769-777.

Fillmore, M. T., \& Rush, C. R. (2006). Polydrug abusers display impaired discrimination-reversal learning in a model of behavioural control. Journal of Psychopharmacology, 20, 24-32.

Fiorino, D. F., \& Phillips, A. G. (1999). Facilitation of sexual behavior in male rats following d-amphetamine-induced behavioral sensitization. Psychopharmacology, 142, 200-208.

Geary, E. H., \& Akins, C. K. (2007). Cocaine sensitization in male quail: Temporal, conditioning, and dose-dependent characteristics. Physiology \& Behavior, 90, 818-824.

Green, A. I., \& Halkitis, P. N. (2006). Crystal methamphetamine and sexual sociality in an urban gay subculture: An elective affinity. Culture Health and Sexuality, 8, 317-333.

Grubbs, F. (1969). Procedures for detecting outlying observations in samples. Technometrics, 11, 1-21.

Kalivas, P. W. (2004). Glutamate systems in cocaine addiction. Current Opinion in Pharmacology, 4, 23-29.

Kalivas, P. W., \& O'Brien, C. (2008). Drug addiction as a pathology of staged neuroplasticity. Neuropsychopharmacology, 33, 166-180.

Kalivas, P. W., Volkow, N., \& Seamans, J. (2005). Unmanageable motivation in addiction: A pathology in prefrontal-accumbens glutamate transmission. Neuron, 45, 647-650.

Kelley, A. E., \& Berridge, K. C. (2002). The neuroscience of natural rewards: Relevance to addictive drugs. Journal of Neuroscience, 22, 3306-3311.

Koob, G. F., \& Volkow, N. D. (2010). Neurocircuitry of addiction. Neuropsychopharmacology, 35, 217-238.

Levens, N., \& Akins, C. K. (2001). Cocaine induces conditioned place preference and increases locomotor activity in male Japanese quail. Pharmacology Biochemistry and Behavior, 68, 71-80.

Levens, N., \& Akins, C. K. (2004). Chronic cocaine pretreatment facilitates Pavlovian sexual conditioning in male Japanese quail. Pharmacology Biochemistry and Behavior, 79, 451-457.

Lorvick, J., Bourgois, P., Wenger, L. D., Arreola, S. G., Lutnick, A., Wechsberg, W. M., \& Kral, A. H. (2012). Sexual pleasure and sexual risk among women who use methamphetamine: A mixed methods study. International Journal of Drug Policy, 23, 385-392.

Mackintosh, N. J. (1974). The psychology of animal learning. London, UK: Academic Press.

Mills, A. D., Crawford, L. L., Domjan, M., \& Faure, J. M. (1997). The behavior of the Japanese or domestic quail Coturnix japonica. Neuroscience \& Biobehavioral Reviews, 21, 261-281.

Morgan, M. A., Romanski, L. M., \& LeDoux, J. E. (1993). Extinction of emotional learning: Contribution of medial prefrontal cortex. Neuroscience Letters, 163, 109-113. 
Murray, J. E., \& Bevins, R. A. (2007). The conditional stimulus effects of nicotine vary as function of training discrimination. Behavioral Pharmacology, 18, 707-716.

Nocjar, C., \& Panksepp, J. (2002). Chronic intermittent amphetamine pretreatment enhances future appetitive behavior for drug- and natural-reward: Interaction with environmental variables. Behavioral Brain Research, 128, 189-203.

Peugh, J., \& Belenko, S. (2001). Alcohol, drugs and sexual function: A review. Journal of Psychoactive Drugs, 33, 223-232.

Pfaus, J. G. (2010). Dopamine: Helping males copulate for at least 200 million years: Theoretical comment on Kleitz-Nelson et al. (2010). Behavioral Neuroscience, 124, 877-880.

Porter, J. N., Olsen, A. S., Gurnsey, K., Dugan, B. P., Jedema, H. P., \& Bradberry, C. W. (2011). Chronic cocaine self-administration in rhesus monkeys: Impact on associative learning, cognitive control, and working memory. Journal of Neuroscience, 31, 4926-4934.

Rawson, R. A., Washton, A., Domier, C. P., \& Reiber, C. (2002). Drugs and sexual effects: Role of drug type and gender. Journal of Substance Abuse Treatment, 22, 103-108.

Reichel, C. M., Murray, J. E., Barr, J. D., \& Bevins, R. A. (2010). Extinction with varenicline and nornicotine, but not ABT-418, weakens conditioned responding evoked by the interoceptive stimulus effects of nicotine. Neuropharmacology, 58, 1237-1245.

Rescorla, R. A. (2000). Extinction can be enhanced by a concurrent excitor. Journal of Experimental Psychology: Animal Behavior Processes, 26, 251-260. doi:10.1037/0097-7403.26.3.251
Robinson, T. E., \& Berridge, K. C. (1993). The neural basis of drug craving: An incentive-sensitization theory of addiction. Brain Research Reviews, 18, 247-291.

Robinson, T. E., \& Kolb, B. (1999). Alterations in the morphology of dendrites and dendritic spines in the nucleus accumbens and prefrontal cortex following repeated treatment with amphetamine or cocaine. European Journal of Neuroscience, 11, 1598-1604.

Russo, S. J., Dietz, D. M., Dumitriu, D., Morrison, J. H., Malenka, R. C., \& Nestler, E. J. (2010). The addicted synapse: Mechanisms of synaptic and structural plasticity in nucleus accumbens. Trends in Neurosciences, 33, 267-276.

Schilder, A. J., Lampinen, T. M., Miller, M. L., \& Hogg, R. S. (2005). Crystal methamphetamine and ecstasy differ in relation to unsafe sex among young gay men. Canadian Journal of Public Health, 96, 340-343.

Semple, S. J., Patterson, T. L., \& Grant, I. (2002). Motivations associated with methamphetamine use among HIV+ men who have sex with men. Journal of Substance Abuse Treatment, 22, 149-156.

Thomas, M. J., Kalivas, P. W., \& Shaham, Y. (2008). Neuroplasticity in the mesolimbic dopamine system and cocaine addiction. British Journal of Pharmacology, 154, 327-342.

Young, K. A., Gobrogge, K. L., \& Wang, Z. (2011). The role of mesolimbic dopamine in regulating interactions between drugs of abuse and social behavior. Neuroscience \& Biobehavioral Reviews, $35,498-515$. 